\title{
Comparison of non-enterprise corporate social responsibility report in domestic and abroad condition
}

\author{
Tao Liu \\ School of North China Electric Power University, Beijing, China \\ Liutao1597050@163.com
}

\begin{abstract}
Keyword: non-profit organization, social responsibility report, at home and abroad, comparison analysis
\end{abstract}

\begin{abstract}
Mainland China released 1521 social responsibility report during Jan 1st, 2013 to Oct 31st, 2013, 13.76 percent higher than the same period last year. And in 2014, mainland China released 2240 social responsibility report, including every kind of industries. With recognition of social responsibility get deeper, more and more organizations issue social responsibility report, of course, the value of report get clearer.

This thesis analyzes similarities and differences of report in disclosing information at home and abroad through researching non-enterprise corporate social responsibility report, and summarize character of non-enterprise corporate social responsibility report. Then, we consider advancement of non-enterprise corporate social responsibility report in abroad and our country's actual conditions, giving these suggestions: Involves stakeholders in constituting the mode of social responsibility report, Combines social responsibility with organization's development, Brings in social responsibility accounting. To help non-profit organizations disclose information people concerned better, and make it true that stakeholders communicate with non-profit organizations, in the final, promote the development of non-enterprise corporate social responsibility report.
\end{abstract}

\section{Introduction}

In the 1970s, there appeared the first social responsibility report at abroad. But because of the economic depression, development of social responsibility report stopped until the 1990's, from then on, social responsibility report at abroad began booming. To make social responsibility report unified, each kind of international organization and association wrote guidelines for the establishment of corporate social responsibility report, such as G3 and SA8000. G3, a sustainable development reportissued by Global Reporting Initiative(GRI) in 2006, had turned into a standard for social responsibility report disclosing information, SA8000, issued in 2001 by Council on Economic Priorities, a non-governmental organization focused on social responsibility and environmental protection, had turned into the first global social responsibility report third-party certification standards. However, the first social responsibility report appeared at 1999 in domestic, and State Grid Corporation of China issued the first social responsibility report of domestic-funded enterprise at 2006. As for non-governmental organization, it appeared later. In summary, the development of non-enterprisecorporate social responsibility report in domestic is about 20 years later than that in abroad. Luckily, the guidelines issued at2012 in Shanghai, Shandong promote the development greatly, and it can make non-enterprisecorporate social responsibility report disclosing information a trend.

From the past researches, we can find most researches focus on social responsibility report of corporation, relatively less on that of non-enterpriseorganization in our country. It shows that corporate issue social responsibility reports 1337, and non-enterprisecorporate issue social responsibility reports 181 as of October 31, 2012 from "GoldenBee CSR China analysis(2006-2012)" and "GoldenBee CSR China analysis(2006-2014)". Through these data, it's obvious that non-enterprisecorporate social responsibilityreports develop slowly, and research on this area is blank. In this case, we using document research and contrastive analysis, write the paper, comparing the difference of non-enterprisecorporate social responsibility report at home and abroad, 
to give some rational suggestions to promote development of non-enterprisecorporate social responsibility report in domestic, and make it in line with international standards, enhancing readability of the report, all based on samples that collected from social responsibility report platform, official website, network search engine and other open channel.

\section{The comparison of guidelines for the establishment of non-enterprise corporate social responsibility report at home and abroad.}

\subsection{The guidelines in abroad.}

We can find that there are three modes of guidelines, by reading non-enterprise corporate social responsibility report of abroad. Those are G3, SA8000 and AA1000. They are unified social responsibility reporting standards all established by international non-governmental organization, owning high acceptance and applicability in the international.

\subsection{The guidelines in the nation.}

Compared with guidelines of abroad, the guidelines in the nation lack unity on the mode, and only in Shanghai, Shandong, some industry association, have the guidelines, look like at least. So, we can find that there doesn't have a unified mode of social responsibility report around our country.

2.3 The comparison of and analysis in constitutor and participants of the guidelines at home and abroad.

Constitutor and participant of guidelines

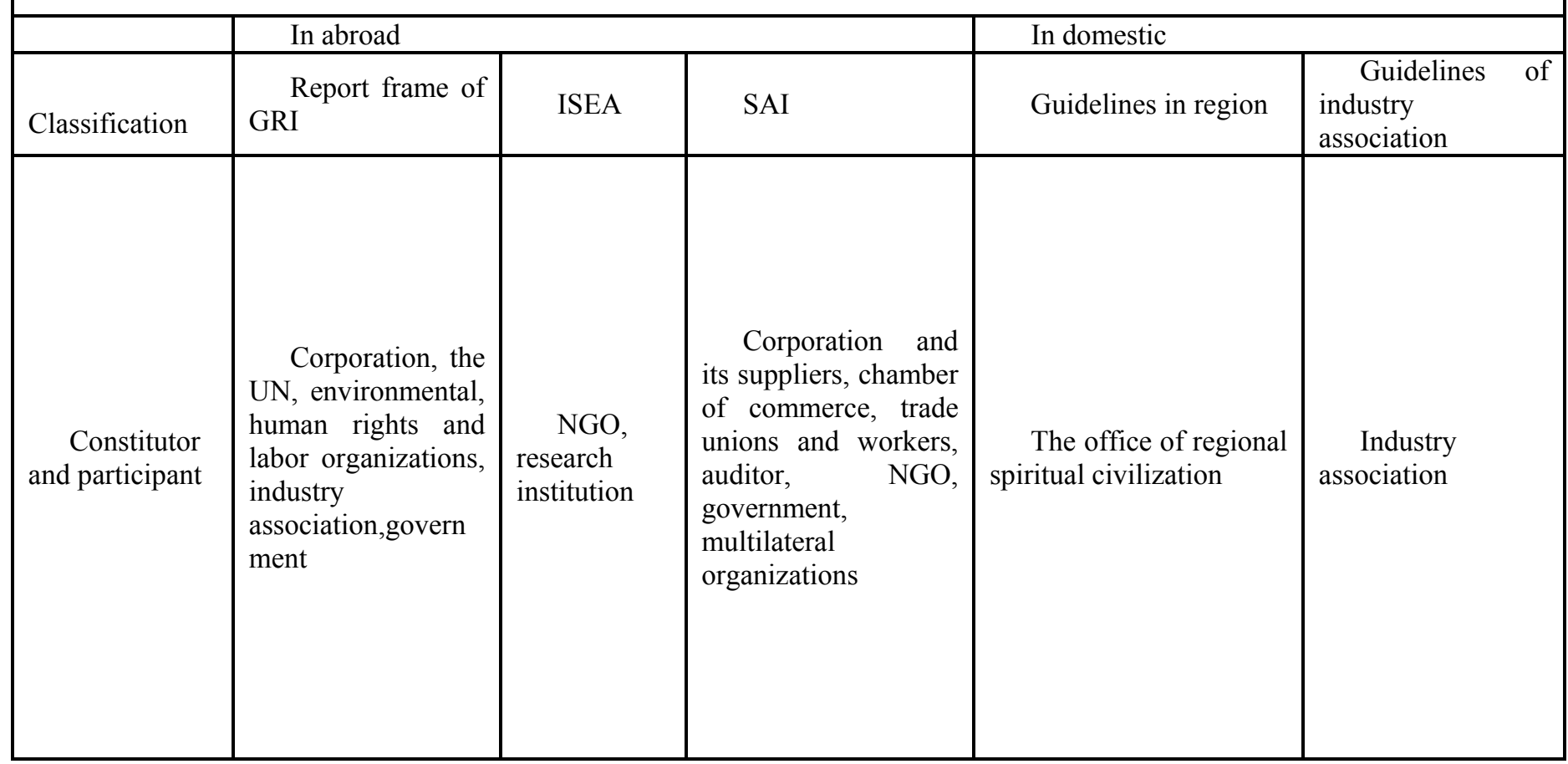

Through the form, we can find that the mode of social responsibility report in abroad is constituted by multi-stakeholder, because stakeholders are the initiative part of getting information and social responsibility report should do best to let it come true. But in our nation, the guidelines is mainly constituted by government and industry association, in this way, profit between non-governmental organizations and stakeholders could be coordinated well, however, stakeholders who should get firsthand information, become passive information receivers, so they can't ask for information they really need in time. 


\section{The comparisons between non-enterprise social responsibility reports at home and abroad in different industries}

\subsection{Educational institution}

Same point:

There are three aspects in the reports, talent training, environment and community, which are focused by educational institutions at home and abroad. Inaddition, all those reports explain the characteristic ofschool's educational philosophy and elaborate efforts in some ways,such as improving teaching quality, protecting teachers and students' rights, building green campus, paying attention to ecology and strengthening the communication with community and so on.

Different points:

1.The reports has their own features at home and abroad

(1)Adding the responsibility of culture to social responsibility reports in our country's colleges in shanghai in 2013.In those reports, they carry forward university's spirit and build up university's culture brand in detail from some ways, like, campus communities, network culture, college students' art base, university's history museums and archives.

(2) There exits the responsibility of economy in reports abroad. They disclose information about source of income and structure of cost with charts. What's more, those reports compare information with the previous year's data, explain the reasons for differences and expound the indirect economic benefits for local and national development.

2. The reports at home and abroad have different emphasis on environmental responsibility.

(1) Environmental indicators selection. Social responsibility reports at abroad mainly collect data from the waste, water and emissions, while the reports at home pay no attention to these. By compared with the previous data, it clearly shows the changes of environmental indicator and reveals the reasons and the next step.

(2) Environmental activities. The reports at home only describe the daily practice, and place emphasis on content and meaning of activities. Educational institutions focus on the environmental protection concept that are Low carbon, energy saving and emissions reducing. In contrast, these relevant activities are viewed as the efforts of improving environmental indicators at abroad.

(3) Environmental activity of sustainability. From the reports at home and abroad, we can find that at abroad there are some relevant projects which have a long duration and are disclosed achievements from year to year and takes the next step and target to improve in social responsibility reports. However, the reports at home usually take short-term project to fulfill responsibilities. Therefore it generates limited scope.

\subsection{Medical Organization}

Same points:

1. Both domestic and foreign social responsibility report are directed to providing quality hospital care, contribution to community and social effect.

2. Both domestic and foreign social responsibility reporthave described the hospital efforts to provide patients with quality care, make efforts to improve the quality of care. Reports introduce the responsibility with specific data from various angles such as purchase of new equipment;improve facilities; the introduction of professionals, etc.

3. Both domestic and foreign hospitals are carrying out charitable activities in the community, providing community consultation, organizing activities such as helping the poor to fulfill community responsibility. Measures taken by hospitals to reduce the prevalence of residents and their spending on health care are beneficial to construct a harmonious doctor-patient relationship. What's more,the honor granted by the State can help the hospital to build a good image and expand the social influence.

Different points:

1.Social Responsibility Report of foreign hospitals elaborate staff responsibility in six aspects which are employee health and safety and welfare, employee benefits, labor relations, employee training, talent strategy, staffing and recruitment. When talking about the staffing and recruitment, it describes the proportion of men and women, the proportion of employees of all ages. As for 
domestic social responsibility report, it doesn't focus on the aspect of the staffing and recruitment, only description it' $\mathrm{s}$ work about protection of employees' rights.

2. For financial responsibility, foreign reports will draw a variety of chart with specific data to disclosure hospital's revenue, expenditure, pay taxes and comparing it with the relevant data of the previous year. As for domestic hospitals report, it rarely involves economic responsibility aspect, and does not relate to a specific amount of money.

\subsection{Government}

Government Social Responsibility Report at home and abroad have paid attention to government information disclosure, specifically the government introduced institutional settings, functions, procedures; work involves the vital interests of citizens, legal persons or other organizations, we need to be widely known or public participation activities.

Different points

1.As the report of the duty of disclosure in the integrity of government responsibility, emphasizing law enforcement, and from the construction work according to the law, individual credit elaborate construction of two angles; but foreign social responsibility report the government is not involved in this.

2.Government Social Responsibility Report at home and abroad in the form of chart data showing revenue and expenditure, the government clearly disclose the purpose of social responsibility in the balance of payments. In contrast, domestic report only describes part of community responsibilities mentioned relief and charitable contributions in fiscal spending.

\section{Learn from advanced international experience and put forward suggestions for our existing problems}

\subsection{Stakeholder involvementtonon-business organizations Social Responsibility Report}

The guidebook ofSocial reportsabroad is written by the stakeholders. So it can directly reflect the information demands of stakeholders. Suggestion of non-business organizations should be carried out in the early issues of interest related to the preparation of the report of the investigation were concerned, asking, make full preparations for the writing of the report; preparation may invite representatives of stakeholders involved in a timely manner to report content improvements, so that the value of reporting information to communicate with stakeholders to maximize benefits at different levels to meet the expectations of the demands of stakeholders; in the disclosure report, promptly inform the stakeholders so that they are kept informed of relevant information. The experiencewhich is learned from domestic and foreign reports can help to form the common development of the non-business organizations.

\subsection{Non-enterprise corporate could combine social responsibility with organization's development.}

Through the research, we can find that non-enterprise corporate in our country focus more on some activities during a short period when compare with that in abroad is preference to long-term activities; it's obvious that long-term activities make a longer-time affect than short-term activities and a closer connection with corporate development. For example, there was a activity about water conservation in a week, in a report of university, as you can see, a week is too short to saving water and other resources like that. Considering this, we suggest that non-enterprise corporate should combine social responsibility with organization's development, by organizing long-term activities, to make social responsibility a real part of organization's development.

\subsection{Non-enterprise corporate could disclose social responsibility with the help of social responsibility accounting.}

There is a feature in non-enterprise corporate social responsibility report abroad, using many data to disclose social responsibility just like social responsibility accounting. Nowadays, social responsibility is mainly used in enterprise, to realize sustainable development and to promote company image of positively performing social responsibility. Social responsibility is a big part of 
non-enterprise corporate, in this way, disclosing social responsibility with the help of social responsibility accounting, is good for report's digitalize and reliability.

\section{Summary}

This thesis analyzes similarities and differences of report in disclosing information at home and abroad through researching non-enterprise corporate social responsibility report classified by different industries, and explores the reason for similarities and differences of report. Then, we consider advancement of report in disclosing information at abroad, also our country's actual conditions, give some suggestions.

This thesis has some deficiencies, mainly on number-limited reports and partiality. Besides, the thesisonly focuses on guidelines and report, instead of report form, quality evaluation and supervision. At last, further study is needed.

\section{References}

[1] Gautier M W.E, Underdown B. Accounting Theory and Practice [M]. Beijing: Higher Education Press, 1996

[2]PhilipKotler. Corporate Social Responsibility [M].Beijing: Mechanical Industry Press, 2006, p.2

[3] XiaojiaCheng. Fiscal Transparency and Government Accounting Reform [J]. Accounting Research, 2004(9), p.22-27

[4] Shanghai civilized units Social Responsibility Report Guidance Manual (Trial)

[5] Jinan City civilized units Social Responsibility Report Guidance Manual (Trial) 